\title{
VALIDAÇÃO DE UM MODELO DE CÁLCULO POR ELEMENTOS FINITOS DO CHASSI DE UMA SEMEADORA DE QUATRO LINHAS
}

\section{BÓRIS K. NIEMCZEWSKI ${ }^{1}$, ÂNGELO V. DOS REIS ${ }^{2}$, ROBERTO L. T. MACHADO ${ }^{3}$, ANTÔNIO L. T. MACHADO ${ }^{4}$}

\begin{abstract}
RESUMO: O comportamento estrutural estático de um chassi experimental de semeadora de quatro linhas para agricultura familiar foi testado, utilizando-se da técnica numérica de Análise de Elementos Finitos, onde se levou em consideração os esforços a que a máquina em questão estaria sujeita, quando suspensa do chão, pelos três pontos de engate do trator. Para a validação do modelo usado pelo software SolidWorks Simulation, submeteu-se um protótipo em escala real do chassi a carregamentos de forças verticais, a fim de comparar os deslocamentos reais da estrutura com os deslocamentos calculados pelo software. Dois estudos foram feitos do modelo para o cálculo dos deslocamentos da estrutura: no primeiro, não foram incluídos os suportes dos engates dos três pontos no cálculo, e os deslocamentos medidos não foram comparáveis com os calculados. No segundo estudo, quando foram incluídos os engates no cálculo, verificou-se que os resultados foram comparáveis com os obtidos na prática. Concluiu-se, portanto, que o segundo estudo é válido e que os cálculos da estrutura do chassi que foram realizados pelo software são confiáveis.
\end{abstract}

PALAVRAS-CHAVE: Mecanização, agricultura familiar, deslocamentos, métodos numéricos.

\section{VALIDATION OF A FINITE ELEMENT CALCULATION MODEL FOR A FOUR-ROW PLANTER FRAME}

\begin{abstract}
The static structural behavior of an four row planter experimental frame for family farming was tested using the Finite Element Analysis numerical technique, which took into account the efforts that this machine would be subjected, when suspended over the ground by the three-point hitch of the tractor. To validate the implemented model by SolidWorks Simulation, a real scale prototype was submitted to vertical loads to compare the actual structural displacement to the software calculated displacement. Two studies were made from the calculation model of structural displacement; in the first, it was not included the three- point hitch brackets for calculation, and the measured displacements were not comparable to the calculated ones. In the second study, when hitches were included in the calculation, the results were comparable to those obtained in practice. Therefore, it was concluded that the second study is valid and the frame structure calculations performed by the software are reliable.
\end{abstract}

KEYWORDS: Mechanization, family farming, displacements, numerical methods.

\section{INTRODUÇÃO}

$\mathrm{Na}$ agricultura familiar, o trabalho é repetitivo, muito cansativo, a mão de obra é reduzida e a mecanização pode ser a solução se bem dimensionada para as tarefas e ao tamanho da propriedade agrícola. Para tratores de baixa potência, na faixa de $18 \mathrm{~kW}$, com tração dianteira auxiliar (TDA), nota-se que há poucas opções de escolha de semeadoras consideradas adequadas no mercado nacional, e que as opções existentes podem não satisfazer às necessidades do agricultor.

Segundo TEIXEIRA et al. (2009), "devido à baixa renda mensal, aliada à pouca oferta por parte dos fabricantes de máquinas agrícolas, os agricultores agroecológicos têm dificuldades em adquirir máquinas e implementos...". "As máquinas e os implementos agrícolas necessários ao

\footnotetext{
${ }^{1}$ Instituto Federal Sul Rio Grandense - Curso de Mecânica, Pelotas, RS. boriskn@ pelotas.ifsul.edu.br

${ }^{2}$ Departamento de Engenharia Rural - Faculdade de Agronomia Eliseu Maciel - UFPel - areis@ ufpel.tche.br

${ }^{3}$ Departamento de Engenharia Rural - Faculdade de Agronomia Eliseu Maciel - UFPel - rlilles@ ufpel.edu.br

${ }^{4}$ Departamento de Engenharia Rural - Faculdade de Agronomia Eliseu Maciel - UFPel - lilles@ufpel.edu.br

Recebido pelo Conselho Editorial em: 30-11-2012

Aprovado pelo Conselho Editorial em: 19-9-2013
} 
agricultor agroecológico são os mais variados, sendo dentre eles destacada a semeadora de milho e feijão..." MACHADO et al. (2007) observaram que os fabricantes de equipamentos de semeadura direta recomendam uma força de tração específica de $7,30 \mathrm{kN}$.linha ${ }^{-1}$, sendo que, em média, a força de tração específica, determinada pela pesquisa de campo, em solo argiloso, é de 2,68 kN.linha ${ }^{-1}$, havendo, portanto, uma superestimativa da força e, logo, da potência necessária.

Ao observar algumas semeadoras de mesmo fabricante, onde há variação do número de linhas de plantio de um modelo para outro, NIEMCZEWSKI et al. (2010) constataram que a maioria das máquinas de pequeno porte disponibilizadas origina-se do projeto de máquinas maiores, o que gera inúmeras inadequações para o uso em pequenas áreas. Os chassis de máquinas maiores são reduzidos em sua largura para se fabricar um modelo com menor número de linhas, mas mantendo o dimensional dos perfis empregados nos projetos de máquinas de grande porte.

NIEMCZEWSKI et al. (2011) analisaram quinze semeadoras de engate de três pontos, agrupando-as em quatro diferentes concepções de semeadoras de baixa potência. Na primeira, o chassi tem um quadro feito de cantoneiras, e na parte frontal, um tubo quadrado e uma plataforma de acesso aos reservatórios de adubo e semente que são separados, um para cada linha. Na segunda concepção, o chassi é um quadro feito de chapa de aço dobrada em "L" nas laterais. Acima, uma plataforma de acesso ao reservatório único de adubo e outra aos reservatórios de sementes, um para cada linha. Na terceira concepção, o chassi é constituído de um tubo quadrado, laterais de chapa na forma triangular que apoiam o reservatório de adubo, único ou individual para cada linha. O reservatório de sementes é fixado na linha. Nas três concepções citadas, duas rodas tracionam os mecanismos de dosagem de adubo e sementes. Na quarta concepção, sobre um tubo quadrado, são montadas as linhas da semeadora, e em cada linha será fixado o reservatório de adubo e de sementes, e no final de cada linha, uma roda compactadora/acionadora dos mecanismos de dosagem de adubo e sementes.

A inexistência de um chassi concebido especificamente para semeadoras-adubadoras de plantio direto de engate de três pontos, voltadas às características dos pequenos agricultores, ou seja, leves, resistentes e com preço acessível, é um problema a ser resolvido.

Atualmente, o uso de técnicas de elementos finitos para dimensionamento de estruturas é amplamente usado. O Método dos Elementos Finitos (MEF) é utilizado para resolver problemas estruturais, térmicos e de vibração, e é possível analisar qualquer forma. Segundo THOMAS (2003): "É crescente a utilização de métodos numéricos para solução de problemas em engenharia."... "A crescente utilização do computador permitiu o desenvolvimento de poderosos métodos e técnicas numéricas para a solução de problemas complexos." FONSECA et al. (2004) desenvolveram uma formulação para a caracterização do estado de tensão e deformação em sistemas tubulares de parede fina utilizando o método dos elementos finitos, comparando com as tensões obtidas num modelo empregando a extensiometria. Segundo eles, "Comparam-se os resultados obtidos com os dos programas comerciais COSMOS $^{\circledR}$ e ANSYS $^{\circledR}$." FONSECA et al. (2004) concluíram: "A estrutura tubular instrumentada permitiu obter resultados comparáveis com os campos de tensão obtidos numericamente. A sobreposição dos deslocamentos devidos à distorção da secção, na formulação do campo de deslocamentos de viga rígida, permite obter resultados comparáveis com outros elementos finitos disponíveis em código, de uma forma fácil e simples".

CALTAROSSO (2008) analisa tensões em equipamento de moagem de cana-de-açúcar, utilizando o MEF com o software Cosmosworks. Com base nos resultados, o castelo de moenda reduziu sua massa em 15\%, que corresponde aproximadamente a $3.000 \mathrm{~kg}$.

O objetivo deste trabalho é validar um modelo de desenho do chassi e de seu protótipo em escala real, submetendo-o a carregamentos verticais (simulação do levante da semeadora pelo engate dos três pontos do trator), empregando um programa de CAD comercial para calcular os deslocamentos da estrutura e possibilitando a comparação dos resultados calculados com os medidos no protótipo. 


\section{MATERIAL E MÉTODOS}

O protótipo testado é de um chassi para uma semeadora-adubadora de quatro linhas, destinada ao plantio direto de milho, soja ou feijão, em pequenas propriedades, que possa ser tracionada por tratores de baixa potência e que empregue o conceito desenvolvido por TEIXEIRA (2009), que utiliza apenas um dosador de sementes para duas linhas de semeadura. Possui reservatórios deslizantes que podem ser deslocados lateralmente e posicionados no centro de duas linhas, já que os dosadores deverão alimentar duas linhas simultaneamente. O sistema deslizante nos tubos do chassi facilita a regulagem nas diferentes distâncias entre linhas de $0,45 \mathrm{~m}$ a $0,75 \mathrm{~m}$. $\mathrm{O}$ chassi foi dimensionado para suportar quatro linhas de plantio, resistir aos esforços máximos de cada sulcador, o peso do adubo e das sementes, bem como seus dosadores e o peso da estrutura. Todo esse cálculo estrutural foi executado pelo software SolidWorks Simulation 2009, que integra o pacote de CAD SolidWorks. O protótipo foi construído em aço de baixo carbono, de acordo com a norma ASTM A36 (American Society for Testing and Materials), para o tubo quadrado principal fabricado em cantoneiras de abas iguais e soldadas com eletrodo revestido, ficando com a medida da secção de 73 x $73 \mathrm{~mm}$ e espessura de $9,5 \mathrm{~mm}$, aço SAE 1010 para os tubos retangulares de $40 \mathrm{x}$ $20 \mathrm{~mm}$ e espessura de $2 \mathrm{~mm}$, e os tubos redondos, com costura de diâmetro externo de $33,7 \mathrm{~mm}$ e espessura de 2,65 mm. Para os engates inferiores, optou-se pelo mesmo material utilizado nas existentes no mercado: barra chata com secção de 76,2 x $12,7 \mathrm{~mm}$, e superiores com secção de 50,8 x $12,7 \mathrm{~mm}$. Toda a estrutura do protótipo foi montada utilizando-se de solda MIG (Metal Inert Gas). A estrutura possui uma configuração triangular hiperestática, onde serão apoiados os dosadores e os reservatórios de adubo e sementes e no tubo quadrado as quatro linhas de plantio.

$\mathrm{Na}$ definição das forças atuantes no sulcador, foram utilizados os dados obtidos por TRÖGER et al. (2012) e ESPÍRITO SANTO et al. (2010). Considerando que, no dimensionamento do chassi, este deverá suportar a pior hipótese de carga, definiu-se a força horizontal em cada sulcador como sendo de $2.500 \mathrm{~N}$, e a força vertical, de $990 \mathrm{~N}$. Na figura 1, é apresentada a distribuição das tensões de von Mises no chassi, empregando na análise elementos de viga e elementos sólidos. A tensão máxima encontrada foi da ordem de $227 \mathrm{MPa}$.
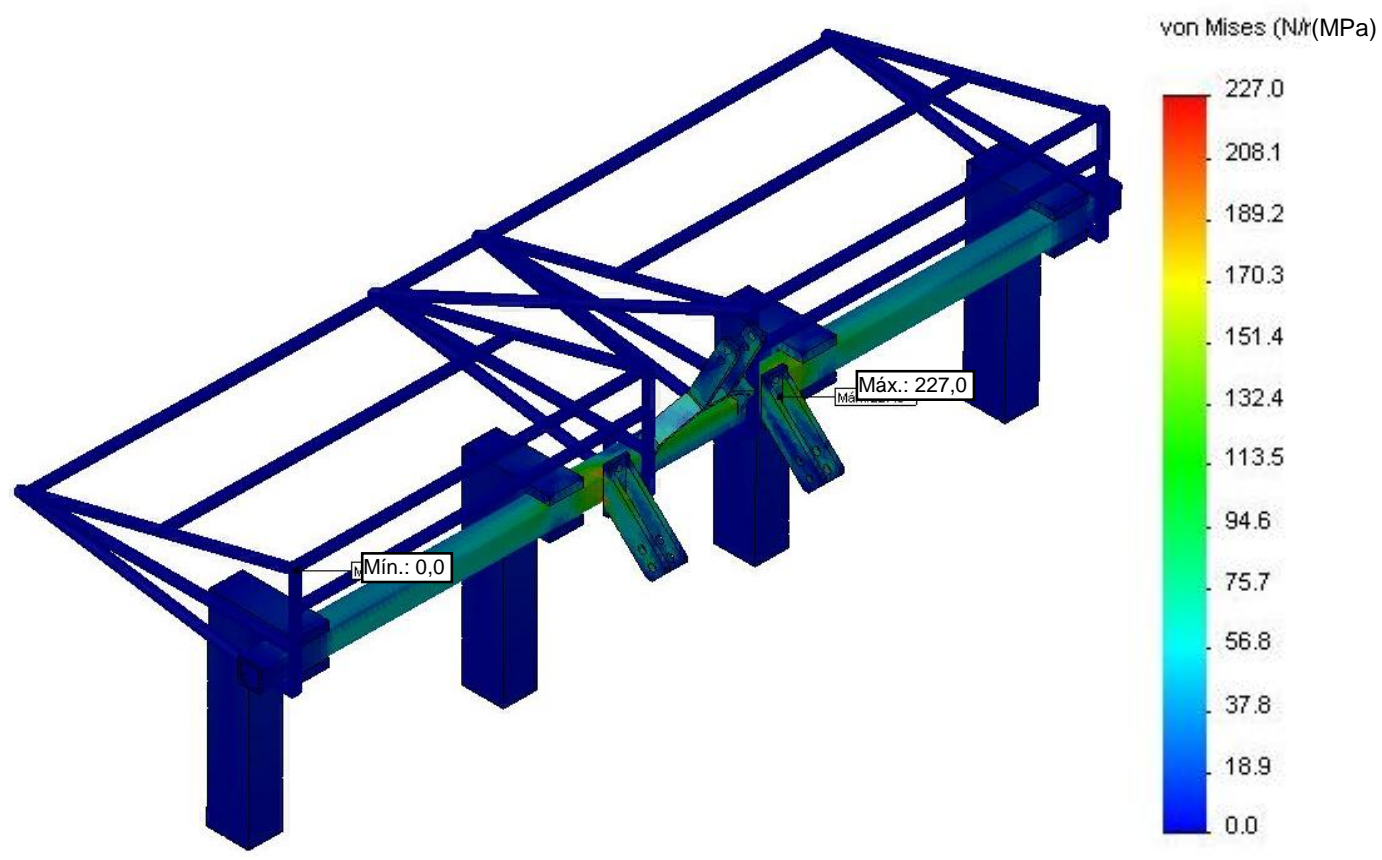

FIGURA 1. Distribuição das tensões no chassi. Distribution of tensions in the frame.

Após executados todos os dimensionamentos, obteve-se um modelo de chassi que é apresentado na Figura 2. 


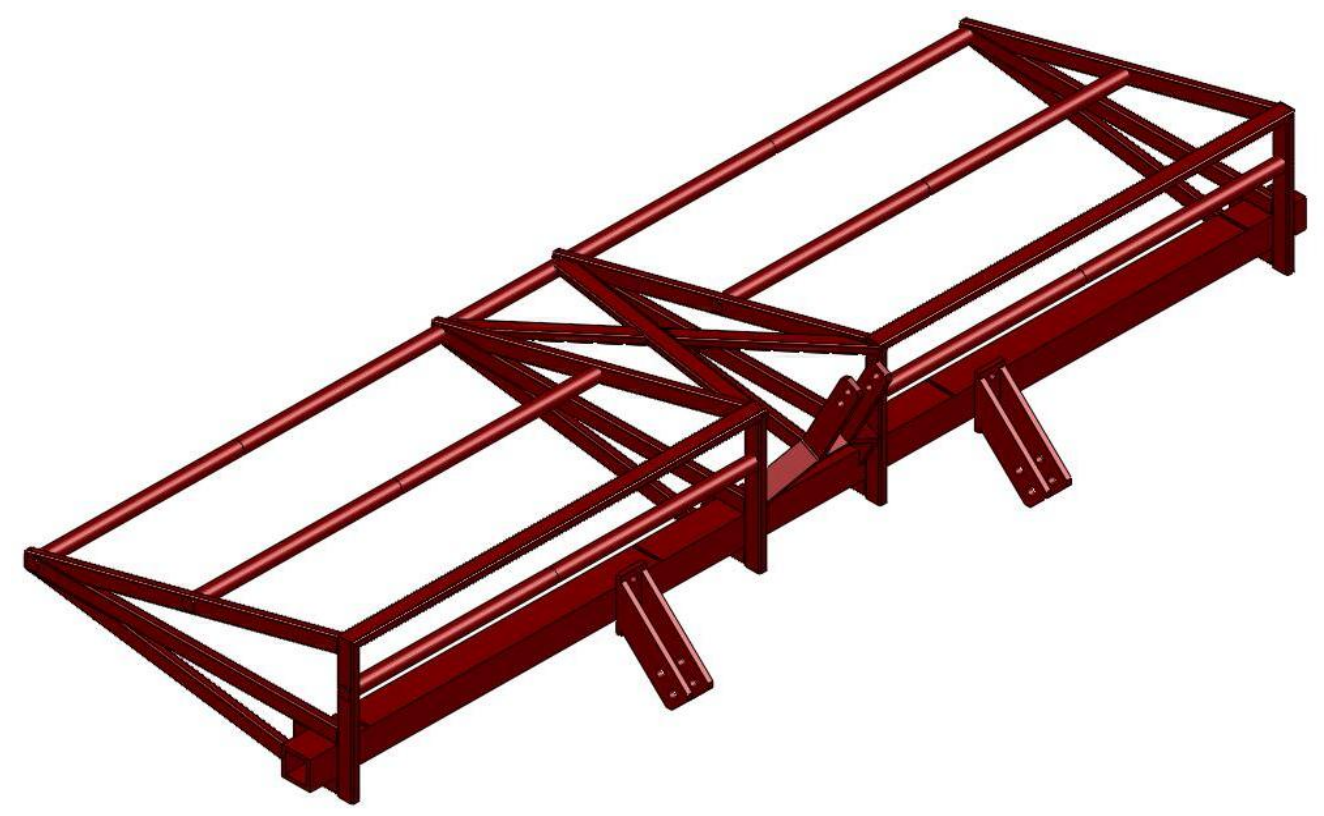

FIGURA 2. Vista Isométrica do chassi. Isometric view of the frame.

Todos os carregamentos para o ensaio no chassi-protótipo foram feitos com as forças verticais, simulando o levantamento da máquina do chão pelos três pontos de engate do trator com carga total.

Para se testar o funcionamento do modelo de cálculo estrutural, foi utilizado um protótipo de chassi em escala real e aplicados os carregamentos verticais de acordo com as mesmas forças e pesos que foram considerados nos cálculos pelo software.

Foram feitas as medições dos deslocamentos da estrutura de acordo com o carregamento real dos pesos correspondentes aos dos dosadores de adubo e reservatórios, pesos dos dosadores de sementes e reservatórios, que foram sendo acrescentados na estrutura até a carga máxima. Também se considerou o peso das quatro linhas em situação de pior hipótese, ou seja, na distância máxima entre linhas; com isso, o carregamento máximo foi de 5.200N. Essas medições de deslocamento da estrutura do chassi foram feitas com relógios comparadores, das marcas Starrett e Mitutoyo, modelo comum, que medem deslocamento máximo de $10 \mathrm{~mm}$, com uma resolução $0,01 \mathrm{~mm}$. Os relógios comparadores são instrumentos de medida usados amplamente pela indústria e servem para comparar medidas de peças fabricadas com uma medida-padrão.

Para se executar os ensaios de deslocamento, a estrutura do chassi foi fixada pelos três pontos de acoplamento em dispositivos que substituem os engates de três pontos do trator. Este dispositivo de fixação (Figura 3) é um bloco de Ferro Fundido, com dimensões externas de 1,00 m x 0,80 m x 0,63 m, e massa aproximada de uma tonelada. Em duas destas faces, estão localizados rasgos em "T", que serviram para posicionar os dispositivos de fixação dos três pontos do chassi. 


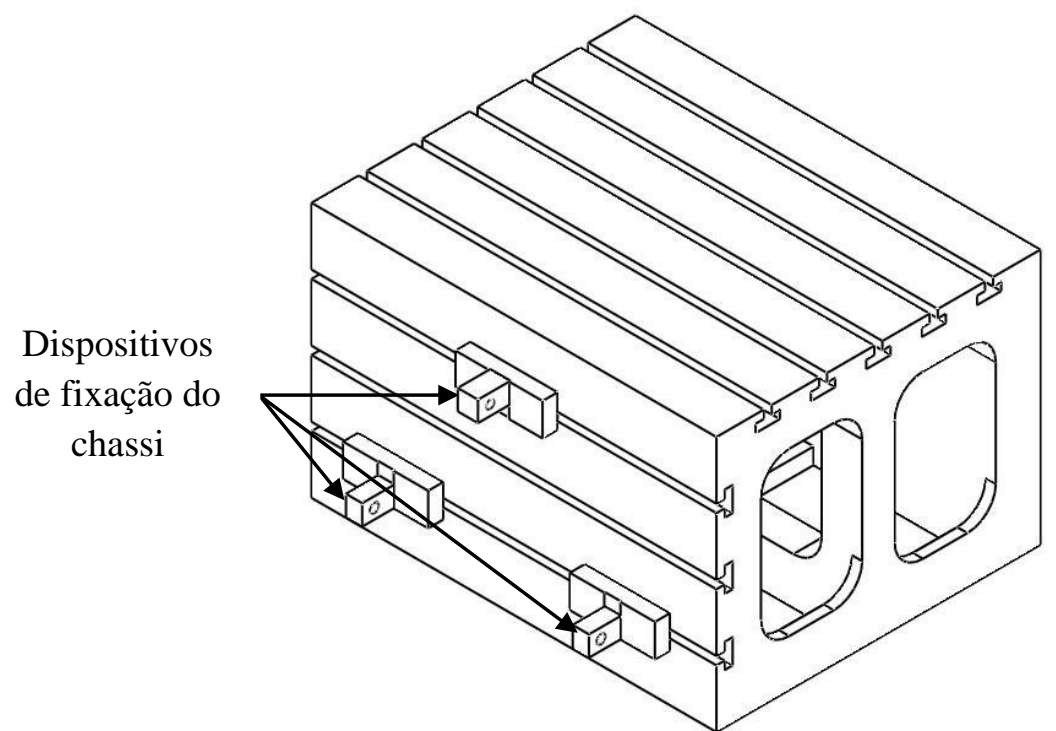

FIGURA 3. Dispositivos de fixação para ensaiar o protótipo do chassi. Fastening devices for testing the prototype of the frame.

Na Figura 4, é mostrado como o chassi foi fixado no bloco de Ferro Fundido, e também o posicionamento dos cabos empregados para pendurar os pesos e os relógios comparadores, para medir os deslocamentos da estrutura.

Em princípio, posicionaram-se os relógios comparadores em três pontos fixos principais na estrutura do chassi, detectados pelo software, que são os pontos de maior deslocamento na estrutura.

Foram feitos dois carregamentos e dois descarregamentos. O primeiro carregamento e descarregamento serviram para estabilizar a estrutura e retirar a folga entre os furos e pinos dos engates de três pontos. Portanto, somente do segundo carregamento e descarregamento é que foram consideradas as medidas dos deslocamentos para posterior comparação com os deslocamentos calculados pelo software SolidWorks Simulation.

A aplicação das cargas no protótipo do chassi e seu posicionamento são mostrados na Figura 5.

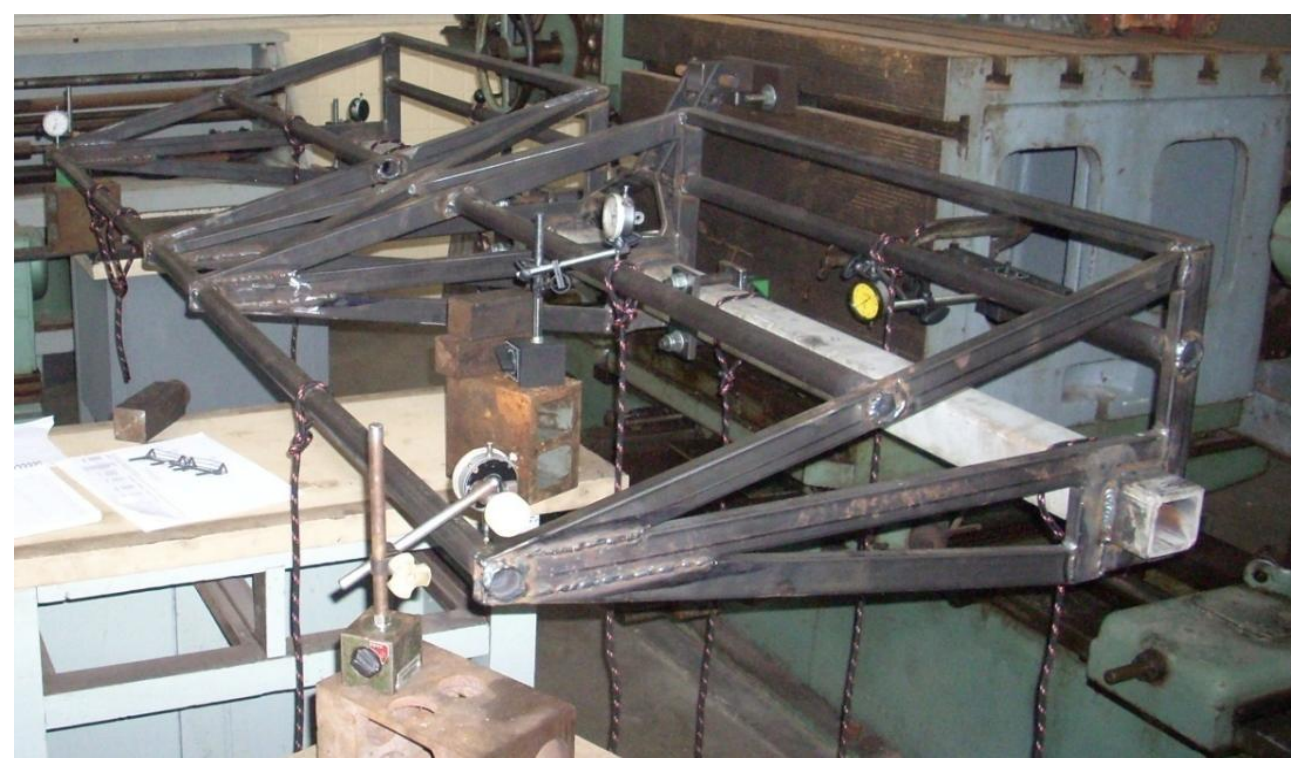

FIGURA 4. Montagem do ensaio - posicionamento dos relógios no chassi e dos cabos para aplicar os carregamentos. Mounting the test - positioning of the dial indicators in the frame and cables to apply the loads. 

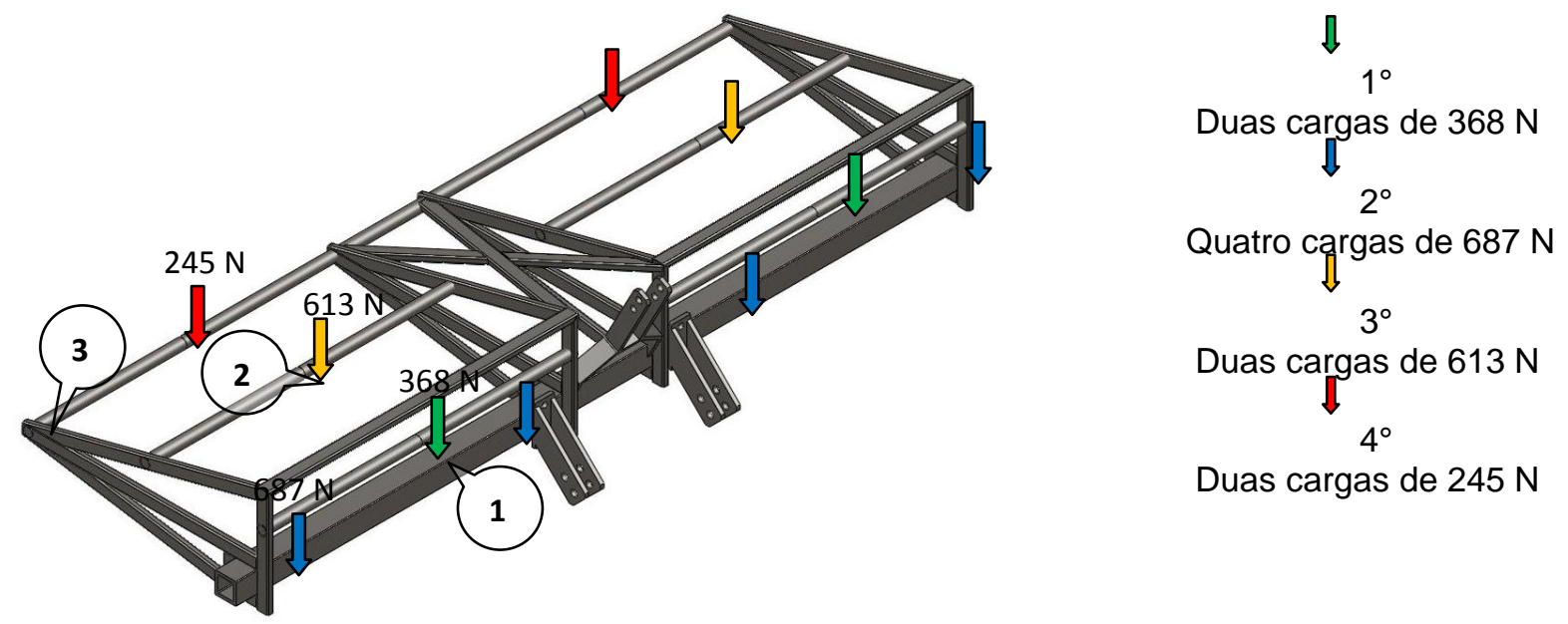

FIGURA 5. Posicionamento das cargas no chassi (setas) e dos relógios comparadores (números de 1 a 3). Position of the loads on the frame (arrows) and of dial indicators (numbers from 1 to 3).

Com os relógios posicionados e zerados, iniciou-se a aplicação das cargas no protótipo do chassi, as quais foram feitas da seguinte forma:

$1^{\circ}$ - Duas cargas de $368 \mathrm{~N}$ - medir deslocamento;

$2^{\circ}$ - Mais quatro cargas de $687 \mathrm{~N}$ - medir deslocamento;

$3^{\circ}$ - Mais duas cargas de $613 \mathrm{~N}$ - medir deslocamento;

$4^{\circ}$ - Mais duas cargas de $245 \mathrm{~N}$ - medir deslocamento.

O carregamento vertical total da estrutura foi de 5.200 N. Para validar o modelo matemático utilizado no software, foram feitos ensaios de carregamento vertical na estrutura do protótipo e o mesmo foi feito na simulação no SolidWorks Simulation, e seus resultados, comparados.

$\mathrm{Na}$ simulação, foram considerados dois modelos de estudo. No primeiro modelo, não foram incluídos os suportes de fixação para o acoplamento dos três pontos do chassi, e os mesmos foram considerados indeformáveis. No segundo modelo, foram incluídos os três suportes de fixação do chassi na análise, considerando-os deformáveis.

As comparações das medidas dos deslocamentos verticais da estrutura do chassi, que foram calculadas pelo software com as medidas observadas pelos relógios comparadores, devem validar o modelo matemático, se forem comparáveis. Com isso, poderemos considerar que os cálculos da estrutura do chassi, que foram realizados pelo software, são confiáveis.

\section{RESULTADOS E DISCUSÕES}

Todos os carregamentos para o ensaio no chassi-protótipo foram feitos somente com as forças verticais, simulando que o mesmo foi suspenso do chão pelos três pontos de engate do trator.

Na Tabela 1, encontram-se os resultados dos deslocamentos na ordem de execução de cada carregamento da estrutura, apresentando os deslocamentos reais medidos e os calculados para as mesmas posições, para comparações. Para este caso, o primeiro modelo não levou em consideração a deformação dos suportes para o acoplamento de três pontos do chassi. Eles foram considerados indeformáveis. 
TABELA 1. Medidas de deslocamentos máximos em cada posição no chassi, real e calculado para o primeiro modelo - carregamento. Measurements of maximum displacements of the frame, real and calculated for the first model - loading.

\begin{tabular}{ccccc}
\hline Carga $(\mathrm{N})$ & \multicolumn{2}{c}{ Deslocamento $(\mathrm{mm})$} & \multicolumn{2}{c}{ Diferença } \\
\hline Posição 1 & Medido & Calculado & $(\mathrm{mm})$ & $(\%)$ \\
736 & 0,52 & 0,54 & $-0,02$ & -4 \\
\hline Posição 2 & & & & \\
4.710 & 3,27 & 2,69 & $+0,58$ & +18 \\
\hline Posição 3 & & & & \\
3.484 & 2,14 & 1,72 & $+0,42$ & +20 \\
5.200 & 4,94 & 3,19 & $+1,75$ & +35 \\
\hline
\end{tabular}

Como se pode verificar na Tabela 1 , somente no carregamento de $736 \mathrm{~N}$, o deslocamento calculado é comparável ao deslocamento real medido, mas o restante dos deslocamentos não apresentaram medidas comparáveis aos calculados.

$\mathrm{Na}$ Tabela 2, são apresentados os valores medidos no chassi e os calculados pelo software SolidWorks Simulation no descarregamento da estrutura, bem como a diferença dos valores de deslocamento. Os valores são apresentados no sentido inverso ao carregamento e também considerando os suportes como indeformáveis.

TABELA 2. Medidas de deslocamentos máximos em cada posição no chassi, real e calculado para o primeiro modelo - descarregamento. Measurements of maximum displacements of the frame, real and calculated for the first model - unloading.

\begin{tabular}{rcccc}
\hline Carga $(\mathrm{N})$ & \multicolumn{2}{c}{ Deslocamento $(\mathrm{mm})$} & \multicolumn{2}{c}{ Diferença } \\
\hline Posição 1 & Medido & Calculado & $(\mathrm{mm})$ & $(\%)$ \\
736 & 0,63 & 0,54 & 0,09 & 14 \\
0 & 0,02 & 0 & 0,02 & - \\
\hline Posição 2 & & & & \\
4.710 & 3,40 & 2,69 & 0,71 & 21 \\
0 & 0,11 & 0 & & - \\
\hline Posição 3 & & & 1,75 & 35 \\
5.200 & 4,94 & 3,19 & 0,60 & 26 \\
3.484 & 2,32 & 1,72 & 0,19 & - \\
0 & 0,19 & 0 &
\end{tabular}

Como se pode verificar na Tabela 2, os valores dos deslocamentos onde o carregamento é até $736 \mathrm{~N}$, os deslocamentos são comparáveis. Como o restante das diferenças (valores de deslocamentos reais medidos menos os valores calculados pelo software) são maiores do que $21 \%$, chegando a 35\%, houve a necessidade de se verificar e refazer o modelo matemático usado, considerando-se a deformação dos suportes dos três engates do chassi.

Na Figura 6, são apresentados os deslocamentos referentes ao segundo modelo matemático, com o carregamento total sobre o chassi de $5.200 \mathrm{~N}$. Na escala de cores, tem-se o deslocamento máximo, na posição 3 , de $4,30 \mathrm{~mm}$. 


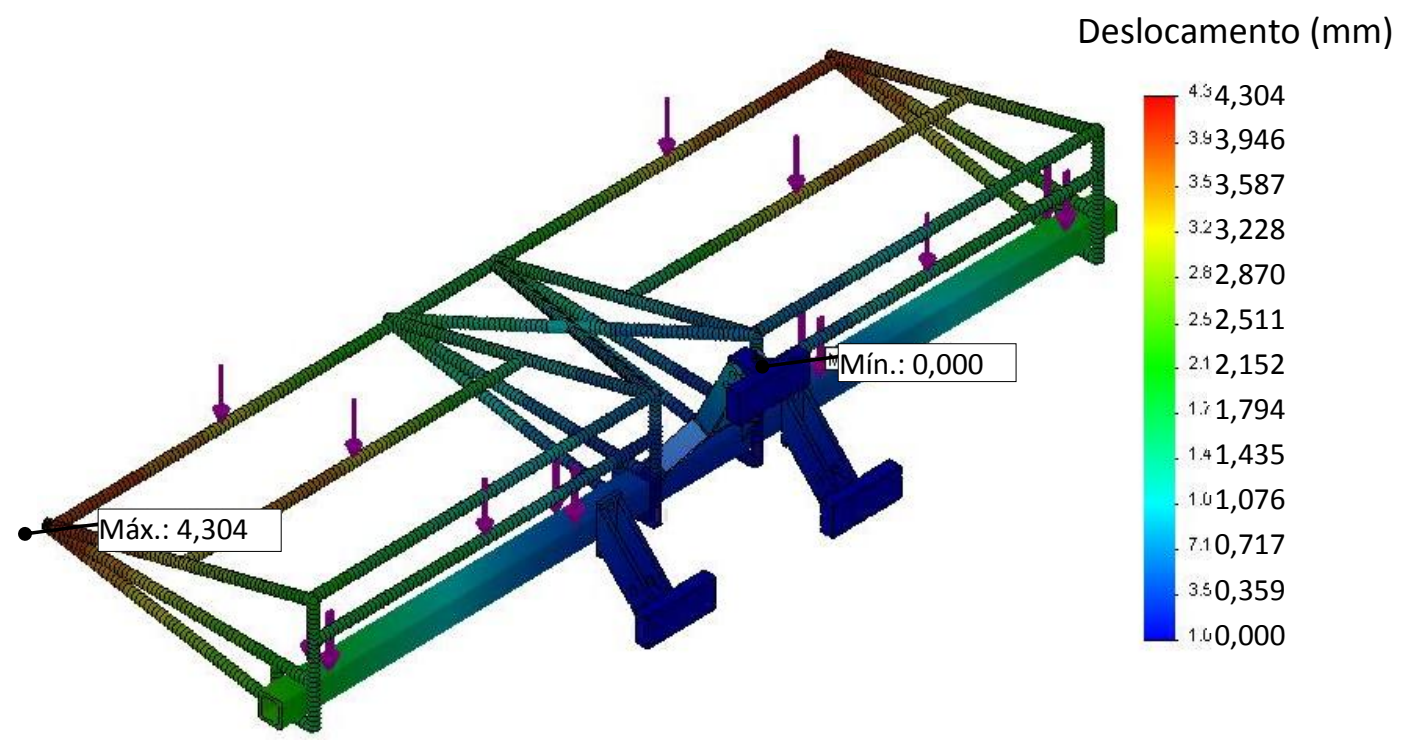

FIGURA 6. Deslocamentos calculados pelo software SolidWorks Simulation. Displacements calculated by SolidWorks Simulation software.

A Tabela 3 apresenta comparações entre as medidas reais e as medidas calculadas pelo software, nas posições 1, 2 e 3, mostradas na Figura 9, para o carregamento da estrutura do chassi, considerando a deformação dos suportes. Observa-se que todas as diferenças entre os valores medidos e calculados para a posição $l$ variam de $-15 \%$ a $12 \%$, ou seja, as diferenças são inferiores a $0,30 \mathrm{~mm}$; para a posição 2 , as quatro diferenças entre os valores medidos e calculados variam de $9 \%$ a $6 \%$, ou seja, as diferenças são inferiores a $0,25 \mathrm{~mm}$; para a posição 3, as quatro diferenças entre os valores medidos e calculados variam de $-4 \%$ a $10 \%$, ou seja, as diferenças são inferiores a 0,45 mm. Portanto, pode-se considerar que este modelo matemático para o carregamento está mais de acordo com as medidas reais de deslocamento do que o modelo anterior.

TABELA 3. Comparações referentes ao carregamento $-2^{\circ}$ modelo. Comparisons for the loading $-2^{\text {nd }}$ model.

\begin{tabular}{ccccc}
\hline & \multicolumn{2}{c}{ Deslocamento $(\mathrm{mm})$} & \multicolumn{2}{c}{ Diferença } \\
\hline Peso $(\mathrm{N})$ & Posição 1 & Calculado & $(\mathrm{mm})$ & $(\%)$ \\
736 & 0,56 & 0,55 & $+0,01$ & +2 \\
3.483 & 1,09 & 1,20 & $-0,11$ & -10 \\
4.709 & 1,38 & 1,59 & $-0,21$ & -15 \\
5.200 & 2,45 & 2,15 & $+0,30$ & +12 \\
\hline 736 & Posição & & & +6 \\
3.483 & 0,17 & 0,16 & $+0,01$ & -9 \\
4.709 & 1,10 & 1,20 & $-0,10$ & +5 \\
5.200 & 3,27 & 3,10 & $+0,17$ & +6 \\
\hline \multicolumn{7}{c}{336} & 3,85 & 3,60 & $+0,25$ & +10 \\
3.483 & Posição 3 & & -3 \\
4.709 & 0,30 & 0,27 & $+0,03$ & -4 \\
5.200 & 2,14 & 2,20 & $-0,06$ & +9 \\
\hline
\end{tabular}

A Tabela 4 apresenta comparações entre as medidas reais, feitas pelos relógios comparadores, e as medidas calculadas pelo software, nas posições 1, 2 e 3 mostradas na Figura 6 para o 
descarregamento da estrutura do chassi, por isso os valores das cargas estão em ordem inversa. Verifica-se que todas as diferenças entre os valores medidos e calculados para a posição 1 variam de $-15 \%$ a $13 \%$, ou seja, as diferenças são inferiores a $0,30 \mathrm{~mm}$; para a posição 2 , das quatro diferenças entre os valores medidos e calculados, três variam de $6 \%$ a $8 \%$, ou seja, as diferenças são inferiores a $0,27 \mathrm{~mm}$; para a posição 3 , das quatro diferenças entre os valores medidos e calculados, três variam de $4 \%$ a $13 \%$, ou seja, as diferenças são inferiores a $0,50 \mathrm{~mm}$; portanto, também se pode considerar que este segundo modelo, para o descarregamento, está mais de acordo com as medidas reais de deslocamento do que o modelo anterior.

TABELA 4. Comparações referentes ao descarregamento $-2^{\circ}$ modelo. Comparisons for the unloading $-2^{\text {nd }}$ model.

\begin{tabular}{ccccc}
\hline & \multicolumn{2}{c}{ Deslocamento $(\mathrm{mm})$} & \multicolumn{2}{c}{ Diferença } \\
\hline Peso $(\mathrm{N})$ & Posição 1 & Calculado & $(\mathrm{mm})$ & $(\%)$ \\
5.200 & 2,45 & 2,15 & $+0,30$ & +12 \\
4.709 & 1,38 & 1,59 & $-0,21$ & -15 \\
3.483 & 1,15 & 1,20 & $-0,05$ & -4 \\
736 & 0,63 & 0,55 & $+0,08$ & +13 \\
0 & 0,02 & 0 & $+0,02$ & - \\
\hline \multicolumn{7}{c}{ Posição } & 3,85 & 3,60 & & +6 \\
5.200 & 3,37 & 3,10 & $+0,25$ & +8 \\
4.709 & 1,28 & 1,20 & $+0,27$ & +6 \\
3.483 & 0,59 & 0,16 & $+0,08$ & +73 \\
736 & 0,09 & 0 & $+0,43$ & + \\
0 & Posição 3,75 & & $+0,09$ & +9 \\
5.200 & 3,97 & 4,30 & $+0,45$ & +13 \\
4.709 & 2,30 & 3,47 & $+0,50$ & +4 \\
3.483 & 0,67 & 2,20 & $+0,10$ & - \\
736 & 0,19 & 0,27 & $+0,40$ & +60 \\
0 & 0 & $+0,19$ & \\
\hline
\end{tabular}

Para uma estrutura maior do que uma viga simples, ou seja, o chassi da semeadora-adubadora do presente estudo, onde se tem uma grande quantidade de cordões de solda, os quais causam tensões pelos aquecimentos e resfriamento, bem como a falta de rigidez da estrutura de fixação do chassi nos três pontos de engate, e considerando as dificuldades de medição dos deslocamentos na prática com os relógios comparadores, admite-se que esse percentual possa variar em torno de $15 \%$. Verifica-se, com isso, que os resultados encontrados são comparáveis aos de FONSECA et al. (2004), que também testaram o modelo de cálculo por elementos finitos com uma estrutura física.

Nas Tabelas 3 e 4, respectivamente, carregamento e descarregamento do chassi, verifica-se que ocorre histerese, que é um fenômeno bastante típico nos instrumentos medidores de deslocamento, como os "relógios comparadores", tendo como fonte de erro, principalmente, folgas nos engates ao bloco (dispositivo de fixação) e deformações associadas ao atrito nos engates. E esse erro é mais evidente no descarregamento da estrutura, especificamente na Tabela 4, para as posições 2 e 3, quando se trata dos menores carregamentos, respectivamente, $735 \mathrm{~N}$ e zero $\mathrm{N}$, onde aparece um percentual da diferença das medidas real e calculada na ordem de 60 e $73 \%$. Assim, parte da diferença observada entre o que foi medido e o que foi calculado, especialmente na posição 3, pode ser atribuída a esse fenômeno.

O software SolidWorks Simulation e todo o algoritmo dessa natureza devem ser usados com muito cuidado para não se cometer eventuais erros na introdução dos dados ou na escolha do modelo adequado à estrutura que será analisada. 


\section{CONCLUSÃO}

Conclui-se que os carregamentos efetuados, tanto nos dois modelos quanto no protótipo apresentam resultados comparáveis que validam o refinamento do modelo.

Conclui-se que o segundo modelo, onde se tem o acréscimo dos dispositivos de fixação dos três pontos do chassi no bloco de Ferro Fundido, tem um comportamento mais adequado com a realidade prática do ensaio.

E por último, conclui-se que o software SolidWorks Simulation utilizado é uma ferramenta eficaz no auxílio dos projetos de estruturas mecânicas.

\section{REFERÊNCIAS}

CALTAROSSO, F. Análise de Tensões em Equipamentos de Moagem da Cana-de-Açúcar usando o Método dos Elementos Finitos. 2008. Dissertação (Mestrado)- Escola de Engenharia de São Carlos, Universidade de São Paulo, São Carlos, 2008.

ESPÍRITO SANTO, A. C.; REIS, A.V.; MACHADO, A. L. T. ; BATISTA, V. J. ; OLDONI, A. Desenvolvimento de um dispositivo para medição de esforços em hastes de semeadoras de plantio direto. Engenharia Agrícola, Jaboticabal, v. 30, p. 288-298, 2010.

FONSECA, E.M.M.; OLIVEIRA, C.A.M de; MELO, F.J.M.Q. de; RIBEIRO, P. Um novo elemento finito de tubo curvo para análise de tubagens tridimensionais. Caso de estudo numérico e experimental. ACE News - Applied Computing Engineering. 3:2, p.78-86, 2004.

MACHADO, R. L. T.; FERREIRA, M. F.; MACHADO, A. L. T.; REIS, A. V.; BUTZKE, H. P. Força de tração de semedoras para plantio direto: informações de campo $\mathrm{X}$ informações de catálogo. TECNO-LÓGICA, Santa Cruz do Sul, v.11, n.1, p.10-12, 2007.

NIEMCZEWSKI, B. K.; REIS, A. V.; MACHADO, A. L. T.; MACHADO, R. L. T. Comparação de Chassi de Semeadoras-Adubadoras por meio de Modelagem Bidimensional. In: CONGRESSO DE INICIAÇÃO CIENTÍFICA, 19², 2010, Pelotas. Anais...

NIEMCZEWSKI, B. K.; REIS, A. V.; MACHADO, R. L. T.; MACHADO, A. L. T. Levantamento de Concepções de Chassis de Semeadoras-Adubadoras Acopladas por Engate de Três Pontos. In: CONGRESSO BRASILEIRO DE ENGENHARIA AGRÍCOLA, 14º, CONBEA, 2011, Cuiabá., Anais...

TEIXEIRA S. S.; MACHADO A. L. T.; REIS A. V.; OLDONI, A. Caracterização da Produção Agroecológica do sul do Rio Grande do Sul e sua Relação com a Mecanização Agrícola. Engenharia Agrícola, Jaboticabal, v.29, n.1, p.162-171, 2009.

THOMAS, C. A. K. Desenvolvimento de um Sistema de Medição de Deformação em Máquinas Agrícolas. 2003. 84 f. Dissertação (Mestrado em Engenharia Mecânica), Escola de Engenharia, Universidade Federal do Rio Grande do Sul, Porto Alegre, 2003.

TROGER, H. C. H.; REIS, A.V.; MACHADO, A. L. T. ; MACHADO, R. L. T. Analyzing the efforts in furrow openers used in low power planters. Engenharia Agrícola, Jaboticabal, v. 32, p. $1.133-1.143,2012$. 